\title{
High prevalence of drug-resistant tuberculosis and other mycobacteria among HIV-infected patients in Brazil: a systematic review
}

\author{
Ricardo H Bammann $1 /{ }^{+}$, Liliana A Zamarioli ${ }^{2}$, Valdir S Pinto', Carla MP Vázquez ${ }^{1}$, Marcelo N Litvoc ${ }^{3}$, \\ Giselle B Klautau', Fernando A Fiúza de Melo $^{4}$, Nilton J Cavalcante', Lucilaine Ferrazoli ${ }^{5}$
}

${ }^{1}$ Instituto de Infectologia Emílio Ribas, São Paulo, SP, Brasil ${ }^{2}$ Instituto Adolfo Lutz, Santos, SP, Brasil ${ }^{3}$ Departamento de Doenças Infecciosas e Parasitárias, Hospital das Clínicas, Faculdade de Medicina, Universidade de São Paulo, SP, Brasil ${ }^{4}$ nstituto Clemente Ferreira, São Paulo, SP, Brasil ${ }^{5}$ nnstituto Adolfo Lutz, São Paulo, SP, Brasil

There is a little-noticed trend involving human immunodeficiency virus (HIV)-infected patients suspected of having tuberculosis: the triple-treatment regimen recommended in Brazil for years has been potentially ineffective in over $30 \%$ of the cases. This proportion may be attributable to drug resistance (to at least 1 drug) and/or to infection with non-tuberculous mycobacteria. This evidence was not disclosed in official statistics, but arose from a systematic review of a few regional studies in which the diagnosis was reliably confirmed by mycobacterial culture. This paper clarifies that there has long been ample evidence for the potential benefits of a four-drug regimen for coinfected patients in Brazil and it reinforces the need for determining the species and drug susceptibility in all positive cultures from HIV-positive patients.

Key words: acquired immunodeficiency syndrome - tuberculosis - drug-resistant - mycobacterial - atypical - Brazil

Despite the progress made in controlling tuberculosis (TB) in Brazil, the rates of case detection and treatment success are still below the global targets (WHO 2008a). Human immunodeficiency virus (HIV)/TB co-infection carries even worse numbers, including unfavorable outcome rates above 60\% (Diniz et al. 2003) and mortality rates above $25 \%$ in some settings (Jamal \& Moherdaui 2007). Illness severity is the major cause of treatment failure among co-infected patients, while lack of compliance to the treatment regimen, drug resistance and nontuberculous mycobacteria (NTM) may also play a role.

Mycobacterial culturing is the gold standard among the available diagnostic methods because it has the highest sensitivity and it allows the species to be determined and the drug susceptibility to be assessed. Mycobacterial culturing (in Löwenstein-Jensen solid medium or automated, when available) is a mandatory laboratory procedure in Brazil for all clinical samples from HIVinfected patients with suspected TB (Conde et al. 2009). However, the samples are not routinely sent for culturing, while few regional facilities are equipped to perform mycobacterial culturing and drug susceptibility testing.

In order to obtain reliable data on the prevalence of drug resistance and NTM among HIV-infected patients, this study has systematically compiled Brazilian studies containing culture-documented TB data.

We carried out a search of the Medline, Latin-American and Caribbean Centre on Health Sciences Information (Lilacs) and Scientific Electronic Library Online

+ Corresponding author: ricbammann@uol.com.br

Received 27 March 2010

Accepted 5 July 2010
(Scielo) databases (in English and Portuguese) in order to conduct a systematic review of the literature related to HIV/TB co-infection in Brazil. The free text terms used were: "AIDS and Tuberculos* and Brazil". The publication years included were from the year 2000 forward. The electronic searches were closed on 1 March 2010. The titles, abstracts and author affiliations were retrieved from the references in each database and those studies in which the diagnosis was confirmed by mycobacterial culture were selected. Based on the selected abstracts, a search was conducted of each article's full text to assess whether the methods clearly established the results for HIV-infected patients under investigation for TB, including mycobacteriological identification and drug susceptibility tests. Two additional criteria were that at least some of the patients had been recruited from the year 2000 forward and at least $70 \%$ of the samples in each study were respiratory samples.

This systematic review was complemented by a manual search of the annals of Brazilian conferences held in this decade on infectious diseases (held every odd year from 2001-2009) and pulmonology (held every even year from 2000-2008), as well as of the annals of the four recent National Tuberculosis Forums (held in 2004, 2006, 2008 and the last one in May, 2010), following the same inclusion criteria.

The Table presents all the selected papers and abstracts. The number of cases in each study corresponds to the number of positive cultures.

Screens of Medline, Lilacs and Scielo yielded 105, 81 and 102 citations, respectively. Twenty-two different citations were considered for full-text review. Of the 22 papers reviewed in full, only eight fulfilled the stated criteria. Six papers were excluded because of the data collection period (not including patients after the year 2000), three articles were excluded because they did not clearly discriminate HIV-positive from HIV-negative results, three 


\section{TABLE}

Rates of drug-resistant tuberculosis (TB) (resistant to at least 1 first-line drug) and isolation of non-tuberculous mycobacteria (NTM) from culture of respiratory samples among human immunodeficiency virus-infected patients in Brazil

\begin{tabular}{|c|c|c|c|c|c|}
\hline References & $\begin{array}{l}\text { Data collection } \\
\text { period }\end{array}$ & $\begin{array}{l}\text { Study } \\
\text { setting }\end{array}$ & $\begin{array}{c}\text { Cases } \\
\mathrm{n}\end{array}$ & $\begin{array}{c}\text { MTB resistant to at least } \\
\text { one drug } \\
\%\end{array}$ & $\begin{array}{c}\text { NTM } \\
\%\end{array}$ \\
\hline Santi et al. (2001) & $1999-2001$ & GenHosp & 39 & 17.9 & 15.4 \\
\hline Bammann et al. (2002) & $2000-2001$ & RefHospAIDS & 348 & 11.9 & 20.4 \\
\hline Liberato et al. (2004) & $1996-2000$ & GenHosp & 16 & 31.3 & NA \\
\hline Coelho et al. (2004) & $1997-2000$ & RefHospAIDS & 216 & NA & 11.6 \\
\hline Lemos et al. (2004) & $2000-2003$ & RefHospTB & 11 & 36.4 & NA \\
\hline Rozman et al. (2007) & $1993-2003$ & RefLabTB & 301 & 11.9 & NA \\
\hline Pedro et al. (2007) & $2000-2006$ & RefLabTB & 144 & 17.5 & 45 \\
\hline Wolfart et al. (2008) & $1997-2003$ & GenHosp & 398 & 17.8 & NA \\
\hline Marques et al. (2008) & $2000-2006$ & RefLabTB & 67 & 25.4 & NA \\
\hline Zamarioli et al. (2009) & $2000-2004$ & RefLabTB & 161 & 14.3 & 24.2 \\
\hline Aguiar et al. (2009) & $2001-2005$ & RefHospTB & 92 & 17.4 & NA \\
\hline Brito et al. (2010) & 2004-2006 & RefHospTB & 111 & 13.5 & NA \\
\hline Nunes et al. (2010) & 2009 & RefLabTB & 55 & 32.7 & 0 \\
\hline
\end{tabular}

GenHosp: general hospital; MTB: Mycobacterium tuberculosis; NA: not assessed; RefHospAIDS: referral hospital for acquired immunodeficiency syndrome; RefHospTB: referral hospitals for TB; RefLabTB: referral laboratory for TB.

papers did not include respiratory samples and two thesis citations were excluded because they have not been published yet. Five additional abstracts were identified by a manual search of the annals of national conferences - two on pulmonology, two on infectious diseases and one from the last National Tuberculosis Forum. The Table summarizes all 13 selected papers and abstracts.

Regarding the geographical region of data collection, most studies came from Southeastern Brazil (9), followed by the South (2), the Northeast and Central-west (1 study of each region). No studies from the North Brazil were selected.

Three studies were performed in general hospitals, three in referral hospitals for $\mathrm{TB}$ and two in referral hospitals for AIDS. Five studies were laboratory-based. Data were collected retrospectively in all the studies but two (Liberato et al. 2004, Brito et al. 2010). Seven studies were designed to enrol both HIV-positive and HIVnegative patients. Eight papers included both pulmonary and extra-pulmonary disease.

Data concerning resistance to specific anti-TB drugs among HIV-infected patients were discernible in seven of the selected studies (Santi et al. 2001, Lemos et al. 2004, Liberato et al. 2004, Rozman et al. 2007, Wolfart et al. 2008, Zamarioli et al. 2009, Nunes et al. 2010). The global resistance rate (both primary and acquired) to isoniazid alone ranged from 3.6-18.7\%, while resistance to rifampicin alone ranged from $0.2-9.1 \%$. Combined resistance to isoniazid and rifampicin ranged from $2-11 \%$.

Concerning NTM, the principal species identified were Mycobacterium avium, Mycobacterium kansasii and Mycobacterium fortuitum (Santi et al. 2001, Bam- mann et al. 2002, Coelho et al. 2004, Pedro et al. 2007).

In Brazil, few studies have addressed the problem of drug-resistant TB. The first national survey on resistance to anti-TB drugs was performed in the middle of the 1990s. At that time, resistant TB was found in $10.6 \%$ of clinical isolates from patients who attended primary health care facilities and multidrug-resistant TB (MDRTB) was found in 2.2\% (Braga \& Hijjar 2003). In response to these findings, government measures enabled the implementation of a national MDR surveillance system (Dalcolmo et al. 2007). A second national survey was begun in 2006 and preliminary data have shown primary and acquired MDR rates of $1.4 \%$ and $7.5 \%$, respectively (Kritski 2010). The World Health Organization reports a $0.9 \%$ rate of MDR-TB among all new cases in Brazil and 5.4\% among previously treated TB cases (WHO 2008b).

Among 2,749 MDR-TB cases reported to the national surveillance system between 1995-2007, 7\% corresponded to HIV-infected patients (Dalcolmo et al. 2007). However, for some reason, TB-drugs resistance regarding HIV-infected patients is not included in the official statistics.

Clinical studies investigating HIV/TB co-infection in Brazil have also been scarce and some of them have only been published in abstract form (in the annals of conferences). The Table demonstrates that among all studies in this review, especially those from Southeastern and Southern Brazil, the proportion of drug-resistant TB samples was high, as was the rate at which NTM were isolated from co-infected patients. It is worth highlighting the fact that in the five studies (Santi et al. 2001, 
Bammann et al. 2002, Pedro et al. 2007, Zamarioli et al. 2009, Nunes et al. 2010) that assessed both outcomes, the proportion of cultures from HIV-infected patients positive for either Mycobacterium tuberculosis resistant to at least one drug or NTM was over $30 \%$.

Although it is difficult to draw comparisons between laboratory-based, hospital-based and population-based studies, taken together these findings are rather worrisome in diagnostic terms and they have clear therapeutic implications.

Among M. tuberculosis isolates, the highest rates of drug resistance were found for isoniazid. Preliminary data from the second national survey on resistance to anti-TB drugs revealed primary and acquired resistance rates to isoniazid of $6 \%$ and $15.3 \%$ and to rifampicin of $1.5 \%$ and $8 \%$, respectively. The MDR rates were $1.4 \%$ and 7.5\%, respectively (Kritski 2010). Among HIVinfected patients, the overall average rates of resistance to isoniazid and to rifampicin varied, but they did not differ much from those of the general population. However, the rate of combined resistance reached over $9 \%$ in three settings (Lemos et al. 2004, Rozman et al. 2007, Nunes et al. 2010).

In addition to reducing early bactericidal activity against replicating mycobacteria, isoniazid resistance might also inhibit rifampicin's sterilizing effect. According to Riska et al. (2000), MDR-TB reflects the progressive accumulation of individual mutations in various independent genes and not the simultaneous acquisition of resistance to multiple drugs. Resistance to one of the drugs develops first, followed by the development of resistance to another drug, eventually resulting in MDRTB. Obviously, the entire process must occur in more than one individual patient, being completed after the transmission of strains among various infected patients, with long-term epidemiological consequences.

The role of drug-resistant TB as a facilitator of the progression to MDR-TB seems to have been neglected and should be given priority. The data shown in the Table reveal high rates of combined resistance, which in Brazil are more commonly attributable to reactivation TB (Melo et al. 2003). Although there is no mention of HIV co-infection, Brazil is among the countries listed as having at least one extensively drug-resistant TB case reported (WHO 2008b).

We believe that inappropriate treatment may have significantly contributed to the high mortality rate associated with HIV/TB co-infection. In addition to the well-known high rates of treatment non-compliance, other aggravating factors include delayed diagnosis and treatment together with a lack of controls over laboratory results and patients' treatment regimens.

One situation that physicians often face in clinical practice is that of an HIV-infected (immunosuppressed) patient suspected of having TB. In such cases, positivity for NTM in a sputum culture, even if not confirmed by laboratory analysis according to the American Thoracic Society (ATS) (Griffith et al. 2007) criteria or any other criteria, is likely to be given considerable weight in the therapeutic decision-making process, which will probably result in the prescription of a specific treatment regimen.
The diagnostic criteria adopted by the ATS emphasize the need for bacteriological identification in samples sent for culturing. In Brazil, as in other countries, the rate of suspicion of pulmonary TB based on a single sputum sample sent for laboratory analysis is quite high - over $65 \%$ of cases, even in referral centres (Zamarioli et al. 2009). Therefore, questions and criticism regarding the identification of these agents (as to whether it indicates simple colonization or disease caused by NTM) are justified and it is imperative that the clinical team be reminded of their obligation to request the additional samples required in order to confirm the diagnosis.

This paper aims to draw attention to the fact that in HIV-infected patients suspected of having pulmonary TB (based on clinical and radiological manifestations or even on the presence of acid-fast bacilli in the sputum), the triple-treatment regimen recommended in Brazil for years has been ineffective in about one-third of the cases. This lack of efficacy is likely due to resistance to at least one drug or to infection with NTM. This evidence is the fruit of routinely sending samples for mycobacterial culture and it acts to reinforce policy for the National Tuberculosis Control Program (NTCP): we need sputum cultures from all HIV-positive patients in addition to all other cases of treatment failure.

Dowdy et al. (2008) constructed a decision-analysis model to estimate the incremental cost-effectiveness of TB culturing from the perspective of a public-sector TB control program. They concluded that TB culturing is a potentially cost-effective tool for use among HIVpositive patients in resource-constrained settings, but integration with existing clinical systems and strengthening of post-analytical processes is required to maximize its impact.

Maruza et al. (2008) suggest that TB treatment of HIV/TB co-infected patients without etiologic confirmation at the discretion of experienced physicians in referral centres did not increase the risk of unfavorable outcomes. However some variables should be closely monitored due to increased risk, for instance: the presence of other opportunistic diseases, a low CD4 lymphocyte count, a high viral load, dyspnoea, disseminated TB and changes in the TB treatment regimen due to adverse reactions or intolerance.

Our results suggests that prescribing empirical treatment without laboratory confirmation of the diagnosis puts a great number of patients at risk for receiving inappropriate treatment, particularly in the context of HIV/ TB co-infection.

The Brazilian NTCP has recently decided to change the current triple-treatment regimen to a four-drug regimen (including rifampicin, isoniazid, pyrazinamide and ethambutol, similar to that employed in the rest of the world). It remains unclear whether this new treatment regimen will increase the rates of treatment success among patients with HIV/TB co-infections. It is also possible that there will now be a greater risk of toxicity and of interaction between the anti-TB drugs and the antiretroviral drugs. There may be some concerns regarding the recommended prophylactic use of isoniazid in HIVinfected patients. However, this increase in the spectrum 
of TB treatment represents a new perspective in the approach to HIV/TB co-infection in Brazil and, combined with the directly observed therapy short-course strategy, it is now essential for treating inadvertent drug-resistant TB and preventing MDR-TB.

This study confirms that there has long been ample evidence of the potential benefits of such treatment for co-infected patients in Brazil. It is also important to stress the need to encourage the adoption of molecular methods for earlier detection of drug-resistant TB and of genotyping for earlier identification of the different mycobacterium species, as well as to reduce the related costs.

\section{REFERENCES}

Aguiar F, Vieira MA, Staviack A, Buarque C, Marsico A, Fonseca L, Chaisson R, Kristski A, Werneck G, Mello F 2009. Prevalence of anti-tuberculosis drug resistance in an HIV/AIDS reference hospital in Rio de Janeiro, Brazil. Int J Tuberc Lung Dis 13: 54-61.

Bammann RH, Vázquez CMP, Haddad DJ, Costa JMS, Souza SA, Souza-Pinto V 2002. Tuberculose resistente e micobactérias não tuberculosas isoladas em 6781 amostras respiratórias consecutivas. J Bras Pneumol 28 (Suppl. 2): S107-108.

Braga JUBA, Hijjar MA 2003. Inquérito epidemiológico da resistência às drogas usadas no tratamento da tuberculose no Brasil 1995-97, IERDTB. Parte III: principais resultados. Bol Pneumol Sanit 11: 76-81.

Brito RC, Mello FC, Andrade MK, Oliveira H, Costa W, Matos HJ, Lourenço MC, Rolla VC, Fonseca L, Ruffino Netto A, Kritski AL 2010. Drug-resistant tuberculosis in six hospitals of Rio de Janeiro, Brazil. Int J Tuberc Lung Dis 14: 24-33.

Coelho AGV, Zamarioli LA, Reis CMPV, Figueiredo TAR 2004. Avaliação dos testes empregados no diagnóstico laboratorial da tuberculose pulmonar em pacientes HIV positivos. Rev Inst Adolfo Lutz 63: 111-115.

Conde MB, de Melo FAF, Marques AMC, Cardoso NC, Pinheiro VGF, Dalcin PTR, Machado Junior A, Lemos ACM, Ruffino Netto A, Durovni B, Sant'Anna CC, Lima D, Capone D, Barreira D, Matos ED, Mello FCQ, David FC, Marsico G, Afiune JB, Lapa e Silva JR, Jamal LF, Telles MAS, Hirata MH, Dalcolmo MP, Rabahi MF, Cailleaux-Cesar M, Palaci M, Morrone N, Guerra RL, Dietze R, de Miranda SS, Cavalcante SC, Nogueira SA, Nonato TSG, Martire T, Galesi VMN, Dettoni VV 2009. III. Diretrizes para tuberculose da Sociedade Brasileira de Pneumologia e Tisiologia. J Bras Pneumol 35: 1018-1048.

Dalcolmo MP, Andrade MK, Picon PD 2007. Tuberculose multirresistente no Brasil: histórico e medidas de controle. Rev Saude Publica 41 (Suppl. 1): 34-42.

Diniz LS, Gerhardt G, Miranda JA, Manceau JN 2003. Efetividade do tratamento da tuberculose em 22 municípios de capitais brasileiras e Distrito Federal. Bol Pneumol Sanit 11: 5-140.

Dowdy DW, Lourenço MC, Cavalcante SC, Saraceni V, King B, Golub JE, Bishai D, Durovni B, Chaisson RE, Dorman SE 2008. Impact and cost-effectiveness of culture for diagnosis of tuberculosis in HIV-infected Brazilian adults. PLoS One 3: e4057.

Griffith DE, Aksamit T, Brown-Elliott BA, Catanzaro A, Daley C, Gordin F, Holland SM, Horsburgh R, Huitt G, Iademarco MF, Iseman M, Olivier K, Ruoss S, von Reyn CF, Wallace RJ Jr, Winthrop K, ATS Mycobacterial Diseases Subcommittee, American Thoracic Society, Infectious Disease Society of America 2007. An official ATS/IDSA statement: diagnosis, treatment, and prevention of nontuberculous mycobacterial diseases. Am J Respir Crit Care Med 175: 367-416.
Jamal LF, Moherdaui F 2007. Tuberculose e infecção pelo HIV no Brasil: magnitude do problema e estratégias para o controle. Rev Saude Publica 41 (Suppl. 1): 104-110.

Kritski AL 2010. Emergência de tuberculose resistente: renovado desafio. J Bras Pneumol 36: 157-158.

Lemos RN, Silva RM, Rosa L 2004. Perfil de resistência primária do Mycobacterium tuberculosis em pacientes com e sem HIV/AIDS internados em um hospital de referência. ACM Arq Catarin Med 33: 48-51.

Liberato IR, de Albuquerque M de F, Campelo AR, de Melo HR 2004. Characteristics of pulmonary tuberculosis in HIV seropositive and seronegative patients in a Northeastern Region of Brazil. Rev Soc Bras Med Trop 37: 46-50.

Marques M, Cunha EAT, Junqueira CT, Bernardes CA, Paniago AMM 2008. Resistência do M. tuberculosis às drogas antituberculose entre pacientes HIV+ em Mato Grosso do Sul - Brasil. J Bras Pneumol 34 (Suppl. 1R): R30.

Maruza M, Ximenes RAA, Lacerda HR 2008. Desfecho do tratamento e confirmação laboratorial do diagnóstico de tuberculose em pacientes com HIV/AIDS no Recife, Pernambuco, Brasil. J Bras Pneumol 34: 394-403.

Melo FAF, Afiune JB, Ide Neto J, Almeida EA, Spada DTA, Antelmo ANL, Cruz ML 2003. Aspectos epidemiológicos da tuberculose multirresistente em serviço de referência na cidade de São Paulo. Rev Soc Bras Med Trop 36: 27-34.

Nunes MAS, Fraga CM, Gomes SF, Ferreira RMC 2010. Coinfecção TB/HIV, levantamento de casos analisados no LACEN - RJ no ano de 2009. In IV Encontro Nacional de Tuberculose, Rio de Janeiro, PO181.

Pedro HSP, Silva MABR, Rossit ARB, Pereira MIF, Goloni MRA, Machado RLD, Franco C, Cordeschi T, Fenley JC 2007. Isolamento de espécies do gênero Mycobacterium sp. entre pacientes portadores de HIV/AIDS em São José do Rio Preto, SP. Braz $J$ Infect Dis 11 (Suppl. 2): S46.

Riska PF, Jacobs WR Jr, Alland D 2000. Molecular determinants of drug resistance in tuberculosis. Int J Tuberc Lung Dis 4 (Suppl. 1): 4-10.

Rozman LM, Santo AH, Rozman MA 2007. Mycobacterium tuberculosis drug resistance in HIV patients in Baixada Santista, São Paulo, Brazil. Cad Saude Publica 23: 1051-1059.

Santi LQ, Valentini MB, Fonseca VF, Garcia GF, Eládio MA, Siqueira AEL 2001. Análises das culturas para micobactérias de pacientes do Hospital Eduardo Menezes - FHEMIG - BH. Braz J Infect Dis 5 (Suppl. 2): S58.

WHO - World Health Organization 2008a. [homepage on the internet]. Anti-tuberculosis drug-resistance in the world. WHO Report 2009 [cited 2009 Sep 1]. Available from: theunion.org/ download/ta/drs_report4_26feb08.pdf.

WHO - World Health Organization 2008b. [homepage on the internet]. Global tuberculosis control. WHO Report 2009. [cited 2009 Oct 20]. Available from: who.int/tb/publications/global_ report/2009/pdf/bra.pdf.

Wolfart M, Barth AL, Willers D, Zavascki AP 2008. Mycobacterium tuberculosis resistance in HIV-infected patients from a tertiary care teaching hospital in Porto Alegre, Southern Brazil. Trans R Soc Trop Med Hyg 102: 421-425.

Zamarioli LA, Coelho AG, Pereira CM, Ferrazoli L, Bammann RH 2009. Identificação laboratorial de micobactérias em amostras respiratórias de pacientes HIV-positivos com suspeita de tuberculose. Rev Soc Bras Med Trop 42: 290-297. 